(C) 2015, Elsevier. Licensed under the Creative Commons Attribution-NonCommercial-NoDerivatives 4.0 International

http://creativecommons.org/licenses/by-nc-nd/4.0/

\title{
The surface chemistry of nanocrystalline MgO catalysts for FAME production: an in situ XPS study of $\mathrm{H}_{2} \mathrm{O}, \mathrm{CH}_{3} \mathrm{OH}$ and $\mathrm{CH}_{3} \mathrm{OAC}$ adsorption
}

\author{
J.M. Montero, ${ }^{b}$ M.A. Isaacs, ${ }^{a}$ A. F. Lee, ${ }^{a}$ J.M. Lynam ${ }^{b}$ and K. Wilson ${ }^{a^{*}}$ \\ ${ }^{a}$ European Bioenergy Research Institute, Aston University, Birmingham B4 7ET, UK. \\ ${ }^{b}$ Department of Chemistry, University of York, Heslington, York, YO10 5DD \\ ${ }^{*}$ Corresponding author: E-mail: k.wilson@aston.ac.uk
}

\begin{abstract}
An in situ XPS study of water, methanol and methyl acetate adsorption over as-synthesised and calcined $\mathrm{MgO}$ nanocatalysts is reported with a view to gaining insight into the surface adsorption of key components relevant to fatty acid methyl esters (biodiesel) production during the transesterification of triglycerides with methanol. High temperature calcined NanoMgO-700 adsorbed all three species more readily than the parent material due to the higher density of electron-rich (111) and (110) facets exposed over the larger crystallites. Water and methanol chemisorb over the NanoMgO-700 through the conversion of surface $\mathrm{O}^{2-}$ sites to $\mathrm{OH}^{-}$and coincident creation of $\mathrm{Mg}-\mathrm{OH}$ or $\mathrm{Mg}-\mathrm{OCH}_{3}$ moieties respectively. A model is proposed in which the dissociative chemisorption of methanol occurs preferentially over defect and edge sites of NanoMgO-700, with higher methanol coverages resulting in physisorption over weakly basic (100) facets. Methyl acetate undergoes more complex surface chemistry over NanoMgO-700, with C-H dissociation and ester cleavage forming surface hydroxyl and acetate species even at extremely low coverages, indicative of preferential adsorption at defects. Comparison of $\mathrm{C}$ 1s spectra with spent catalysts from tributyrin transesterification suggest that ester hydrolysis plays a key factor in the deactivation of $\mathrm{MgO}$ catalysts for biodiesel production.
\end{abstract}

\section{Introduction}

Global energy security and environmental concerns related to widely accepted anthropogenic climate change are key challenges facing both developed and emerging nations. Despite significant growth in proven and predicted fossil fuel reserves (notably through heavy crude oil, tar sands, deep water wells, and shale oil and gas), there is growing evidence that an increasing proportion of any such nonrenewable carbon resources (estimates vary between 65-80\%[1, 2]) cannot be burned without breaching the UNFCC targets for a $2{ }^{\circ} \mathrm{C}$ increase in mean global temperature relative to the preindustrial level by 2100.[3, 4] Biomass, derived from non-edible sources of lignocellulose, sugars, and triglycerides offer the only sustainable and low cost solutions to alternative low carbon/carbon neutral transportation fuels. Thermal processing of lignocellulosic biomass to alkanes via pyrolysis and 
hydrodeoxygenation $(\mathrm{HDO})[5,6]$ or the conversion of plant or algae oil lipids via transesterification $[7$, 8] to biodiesel are the subject of many investigations targeting low cost renewable transportation fuel.[9] While biodiesel production via the transesterification of $\mathrm{C}_{14}-\mathrm{C}_{20}$ triglyceride (TAG) components of lipids with $\mathrm{C}_{1}-\mathrm{C}_{2}$ alcohols[10-13] into fatty acid methyl esters (FAMEs) routes offer an energetically economical route to biofuels,[14],[15] the use of soluble base catalysts results in fuel contamination and accompanying reactors and engine manifold corrosion. Complete removal of alkali components from biodiesel is particularly problematic and energy intensive, requiring aqueous quench and neutralisation steps which result in the formation of stable emulsions and soaps.[9, 16, 17] Life-cycle calculations on biodiesel synthesis from soybean feedstock show that the catalytic conversion of TAGs into biodiesel is the single most energy intensive step, accounting for $87 \%$ of the total primary energy input,[18] largely a consequence of these associated quench and separation steps.

Heterogeneous catalysis has a rich history of facilitating energy efficient selective molecular transformations, and contributes to around $90 \%$ of chemical manufacturing processes and more than $20 \%$ of all industrial products. $[19,20]$ Technical advances in catalyst and reactor design underpin the current and future utilisation of inedible biomass feedstocks, and are essential for biodiesel to remain a key player in the renewable energy sector for the foreseeable future. The utility of solid base catalysts for biodiesel production has been widely reported[7, 12, 21-23], wherein they offer improved process efficiency by eliminating the need for quenching steps, and permit continuous operation.[24] Despite industrial and academic interest in the development of solid base catalysts for biodiesel synthesis, to date, there are no surface investigations on the interaction of esters and alcohols over relevant practical catalysts.

The first step in base-catalysed transesterification (Scheme 1) is believed to be activation of the alcoholic solvent by the base to form an alkoxide anion.[16] The alkoxide group is considered to be the catalytically active species in transesterification,[25] attacking the electrophilic carbonyl group of the TAG to form a tetrahedral intermediate yielding the alkyl ester product.[26] The catalytic cycle is completed by the resulting diglyceride reacting with the protonated base to regenerate the catalyst. 

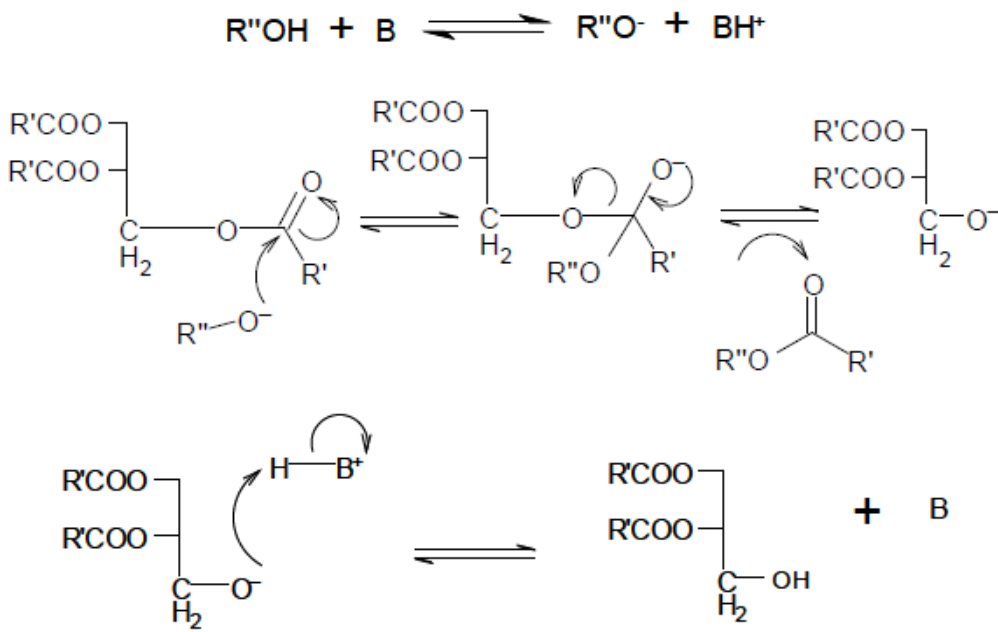

Overall:

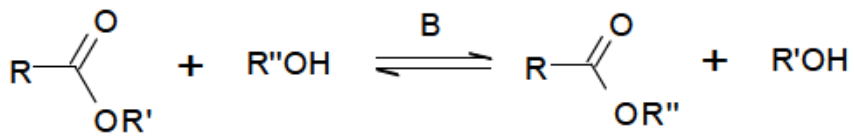

Scheme 1: Mechanism of base catalysed transesterification of triglycerides with alcohol. $R=$ glyceride moiety, $\mathrm{R}^{\prime}=$ carbon chain of the fatty acid and R" = alkyl chain of the alcohol.

Nanocrystalline $\mathrm{MgO}$ is an excellent solid base catalyst for the transesterification of triglycerides in the production of biofuels, with activity proportional to base site strength.[27, 28] It has been previously reported that (111) facets of nanocrystalline $\mathrm{MgO}$ are the most active for this reaction due to their enhanced basicity, with the density of strong base sites enhanced through thermal treatment.[27, 28] $\mathrm{MgO}$ adopts a rock salt structure for which the (100) facet is favoured thermodynamically. The basicity of such oxides arises from either surface defects formed by $\mathrm{Mg}^{2+}$ vacancies, or the presence of lower coordination (110) and (111) facets. The least energetically stable (111) surface exhibits a net dipole moment since it consists of alternating $\mathrm{O}^{2-}$ and $\mathrm{Mg}^{2+}$ ion layers, with an oxygen termination expected on exposure to air.[29] In contrast, the non-polar (110) and most stable (100) facets consist of $\mathrm{Mg}^{2+-} \mathrm{O}^{2-}$ pairs. For the (110) facet, the $\mathrm{O}^{2-}: \mathrm{Mg}^{2+}$ ratio is higher than that for the (100) facet, with the (111) facet expected to be the most electron-rich of these three low-index $\mathrm{MgO}$ surfaces due to its higher anion concentration. $\mathrm{MgO}$ crystals that expose a greater proportion of electron-rich (111) and (110) facets would therefore be expected to exhibit superior Lewis basicity than crystals dominated by (100) facets.

$\mathrm{MgO}$ surfaces are known to exhibit a range of defects.[30].[31] For example, surface reconstruction during annealing can generate point defects,[32] such as cationic vacancies, and low-coordination anionic sites (e.g. corner, step, edge or kinks) which are more polarisable and therefore exhibit higher Lewis basicity (Scheme 2).[29] MgO has been identified as a promising catalyst for soya bean, sunflower and vegetable oil transesterification,[33-35] although commercially sourced $\mathrm{MgO}$ typically possesses a low surface area and hence is an ineffective solid base catalyst for TAG transesterification.[36] This poor performance has driven the development of new $\mathrm{MgO}$ architectures and presentation formats which afford higher surface areas in an attempt to improve its reactivity 
towards various catalytic processes.[37-39] Although the general consensus is that the efficacy of solid base catalysts in triglyceride transesterification is favoured by stronger basic sites at the catalyst surface, $[34,40]$ the influence of surface basicity upon catalytic activity remains poorly understood, hampering further catalyst optimisation and the commercial exploitation of $\mathrm{MgO}$ in biodiesel production.

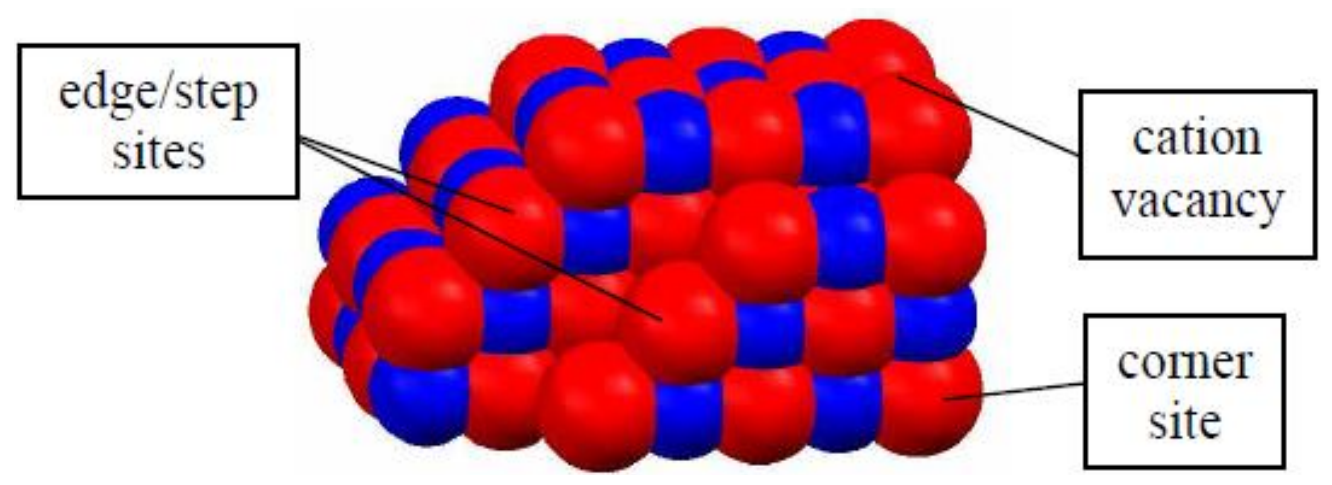

Scheme 2: Typical defects found on the surface of $\mathrm{MgO}$

Adsorption of small, polar molecules over single crystal and thin film $\mathrm{MgO}$ surfaces is well-established in the literature,[41-58] however the majority of studies focus on the most stable (100) surface.[30, 5969] It has been established through both theoretical and experimental methodologies that well-defined and atomically flat $\mathrm{MgO}(100)$ terraces do not readily interact with, or dissociatively adsorb, a number of adsorbates including carbon dioxide[59], water,[60-66] methanol,[67] formaldehyde,[68] methyl formate[66] and formic acid[66] at room temperature. Indeed, any observed adsorption over this facet appears due to the presence of low-coordinate defects on the oxide surface, as evidenced by studies in which defects are deliberately introduced through ion bombardment.[60,67]

Efforts to study adsorption over the less stable/more electron-rich (111) surface[60, 62, 66, 68, 70] have proven problematic due to surface reconstruction resulting in a highly facetted termination. [71, 72] In spite of this difficulty, adsorption studies over the highly stepped (111) surface which contains a high proportion of corner sites,[72] have provided a useful contrast to the comparatively atomically smooth (100) terraces. Dissociative adsorption of water, small acids, aldehydes and alcohols is more prevalent over reconstructed (111) surfaces than (100) counterparts.[59], [60, 62, 66, 70] To our knowledge, there are no complementary adsorption studies over high area $\mathrm{MgO}$ powder catalysts, which due to their polycrystalline nature, may exhibit multiple surface terminations. Here we explore the adsorption of $\mathrm{H}_{2} \mathrm{O}, \mathrm{MeOH}$ and $\mathrm{MeOAc}$, relevant to TAG transesterification over well-characterised and catalytically active $\mathrm{MgO}$ nanocrystals[28, 73] with a view to providing fundamental insight into interaction of key reactive functionalities with practical $\mathrm{MgO}$ catalyst surfaces.

\section{Experimental}

\subsection{Nanocrystalline magnesium oxide}


Commercial nanocrystalline magnesium oxide NanoMgO (99.6\%, NanoActive Magnesium Oxide Plus, NanoScale Corporation) was sintered at different temperatures in order to create a series of catalysts with different particle size/morphology. Samples were heated at $5{ }^{\circ} \mathrm{C} \cdot \mathrm{min}^{-1}$ to temperatures between 300 and $700{ }^{\circ} \mathrm{C}$ (designated by NanoMgO-XXX) under a helium flow of $10 \mathrm{ml} \cdot \mathrm{min}^{-1}$, and maintained at the set temperature for $5 \mathrm{~h}$. Helium was employed to promote the formation of defects in the $\mathrm{MgO}$ surface during the annealing process as previously described [39]. Materials were subsequently stored in vacuo until required.

\subsection{In situ XPS}

XPS was performed on a Kratos Axis HSi X-ray photoelectron spectrometer fitted with a charge neutralizer and magnetic focusing lens, employing Al $\mathrm{K}_{\alpha}$ monochromated radiation $(1486.7 \mathrm{eV})$ at 40 $\mathrm{eV}$ analyser pass energy and normal emission. Spectral fitting was performed using CasaXPS version 2.3.14. Sample charging was minimised using a magnetic charge neutralisation system, and binding energies were referenced to adventitious carbon at $284.6 \mathrm{eV}$, with surface atomic compositions calculated via correction for the appropriate instrument response factors. XP spectra were fitted using a common Gaussian-Lorentzian (70:30) asymmetric lineshape. FWHM and peak positions were fixed across each adsorption series, and the minimum number of peaks required to achieve a good fit was used in all cases. Confidence limits for fitted XP components were established through repeated fitting employing slight variations in the initial background subtraction and fitted parameters. This careful optimisation afforded narrow confidence limits of \pm 0.1 atom\% for all reported values. Samples were loaded into a bespoke holder, and temperature-dependent $O$ and $C$ 1s XP spectra and O KLL Auger spectra recorded within the main analysis chamber while maintaining a base pressure of $1 \times 10^{-9}$ Torr. Samples were heated in vacuo to the desired temperature between $300-700^{\circ} \mathrm{C}$ at a slow rate $\left(2{ }^{\circ} \mathrm{C}\right.$.min1) to minimise sample outgassing. Samples were held at the desired temperature for $30 \mathrm{~min}$ to thermally equilibrate, prior to cooling and then exposure to deionised water, methanol (ACS reagent grade, Fisher) or methyl acetate $\left(\mathrm{CH}_{3} \mathrm{C}(\mathrm{O}) \mathrm{OCH}_{3}, \geq 99.8 \%\right.$, Sigma Aldrich). Liquids were purified via freezepump-thaw cycles prior to dosing. NanoMgO-700 was prepared in situ by heating the parent in vacuo NanoMgO to $700{ }^{\circ} \mathrm{C}$ for $30 \mathrm{~min}$. Exposure to each adsorbate is quoted in Langmuirs (L) where $1 \mathrm{~L}$ is defined as an exposure of $1 \times 10^{-6}$ Torr for 1 second. To aid visualisation of changes in surface composition with gas exposure, compositional differences were calculated according to Equation 1:

Compositional difference $(\%)=100 \times\left[\frac{(\text { Atomic \% after exposure })-(\text { Atomic } \% \text { of parent })}{(\text { Atomic } \% \text { of parent })}\right]$

Equation 1

\section{Results and Discussion}

Synthesis of size-controlled $\mathrm{MgO}$ nanocatalysts was previously reported through calcination of a commercially prepared parent nanocrystalline MgO (labeled NanoMgO) between 300 and $700{ }^{\circ} \mathrm{C}$. Surface areas and powder XRD/TEM crystallite diameters are summarized in Table 1. As anticipated, 
higher annealing temperatures progressively decrease the BET surface area while increasing the crystallite size, consistent with thermal sintering.

Table 1. MgO catalyst surface areas and crystallite sizes determined by XRD and TEM (Reproduced from [28])

\begin{tabular}{|c|c|c|c|}
\hline Sample $^{a}$ & $\begin{array}{l}\text { Surface area } \\
\qquad / \mathrm{m}^{2} \cdot \mathrm{g}^{-1}\end{array}$ & $\begin{array}{l}\text { Mean crystallite size (XRD) } \\
\qquad / \mathrm{nm}\end{array}$ & $\begin{array}{l}\text { Crystallite range (TEM) } \\
\qquad / \mathrm{nm}\end{array}$ \\
\hline NanoMgO & 580 & 2.8 & $2.6 \pm 0.6$ \\
\hline NanoMgO-400 & 360 & 5.1 & $6 \pm 2$ \\
\hline NanoMgO-500 & 250 & 7.3 & $8 \pm 2$ \\
\hline NanoMgO-600 & 140 & 10.8 & $11 \pm 2$ \\
\hline NanoMgO-700 & 80 & 16.5 & $16 \pm 4$ \\
\hline
\end{tabular}

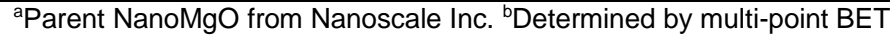

Oxygen Auger parameter measurements $(\alpha)$ offer an effective tool for determining the surface polarizability of metal oxides,[74] and are calculated as the difference in energy between the $O 1 \mathrm{~s}$ binding energy and O KLL Auger transition according to Equation 2.

Auger parameter $(\alpha)=\mathrm{KE}$ (Auger $\mathrm{e}^{-}$from photoelectron) $+\mathrm{BE}$ (photoelectron)

Equation 2

Such methods have been shown to provide a quantitative determination of surface basicity in nanocrystalline $\mathrm{MgO},[28]$ whose size and surface termination have been tuned to change surface basicity. The change in the Auger parameter for such samples correlated with catalytic reactivity in the transesterification of glyceryl tributyrate (a short chain model of the saturated triglycerides found in plant oils) with methanol as summarised in Fig $\mathbf{1}$ suggesting this is a reliable indicator of catalyst basicity. $\triangle E_{k}$ is a complementary measure of polarizability related to the energy difference between $O K L_{23} L_{23}$ and $O K_{1} L_{23}$ transitions as illustrated in Fig 1a which shows a representative O KLL Auger spectrum for the parent NanoMgO, which exhibits characteristic features from the $\mathrm{Mg}(\mathrm{OH})\left(\mathrm{OCH}_{3}\right)$ precursor material, in addition to $\mathrm{MgO}$ and $\mathrm{MgCO}_{3}$ (the latter arising from atmospheric $\mathrm{CO}_{2}$ capture). Strong size dependent variations in $\triangle E_{k}$ and $\alpha$, and hence surface polarizability, are apparent for MgO crystallites between 3-10 nm in Fig 1 b, with no further changes upon additional sintering. A detailed study of the catalytic performance of these materials in glyceryl tributyrate transesterification (experimental details can be found in ref [28]), revealed that after $24 \mathrm{~h}$ reaction conversion varied from 60 to $80 \%$ across the NanoMgO series, achieving a maximum for crystallites around $5 \mathrm{~nm}$. Fig. 1c summarises the correlation between catalyst structure and performance, which reveal a striking linear correspondence between surface area normalised initial rates of tributyrin transesterification and surface polarity $\left(\triangle E_{k}\right)$; $\mathrm{Mg}(\mathrm{OH})\left(\mathrm{OCH}_{3}\right), \mathrm{Mg}(\mathrm{OH})_{2}$ and $\mathrm{MgCO}_{3}$ were themselves inactive for tributyrin transesterification, hence trace levels of these surface species exert negligible influence on this correlation.

a)

b) 


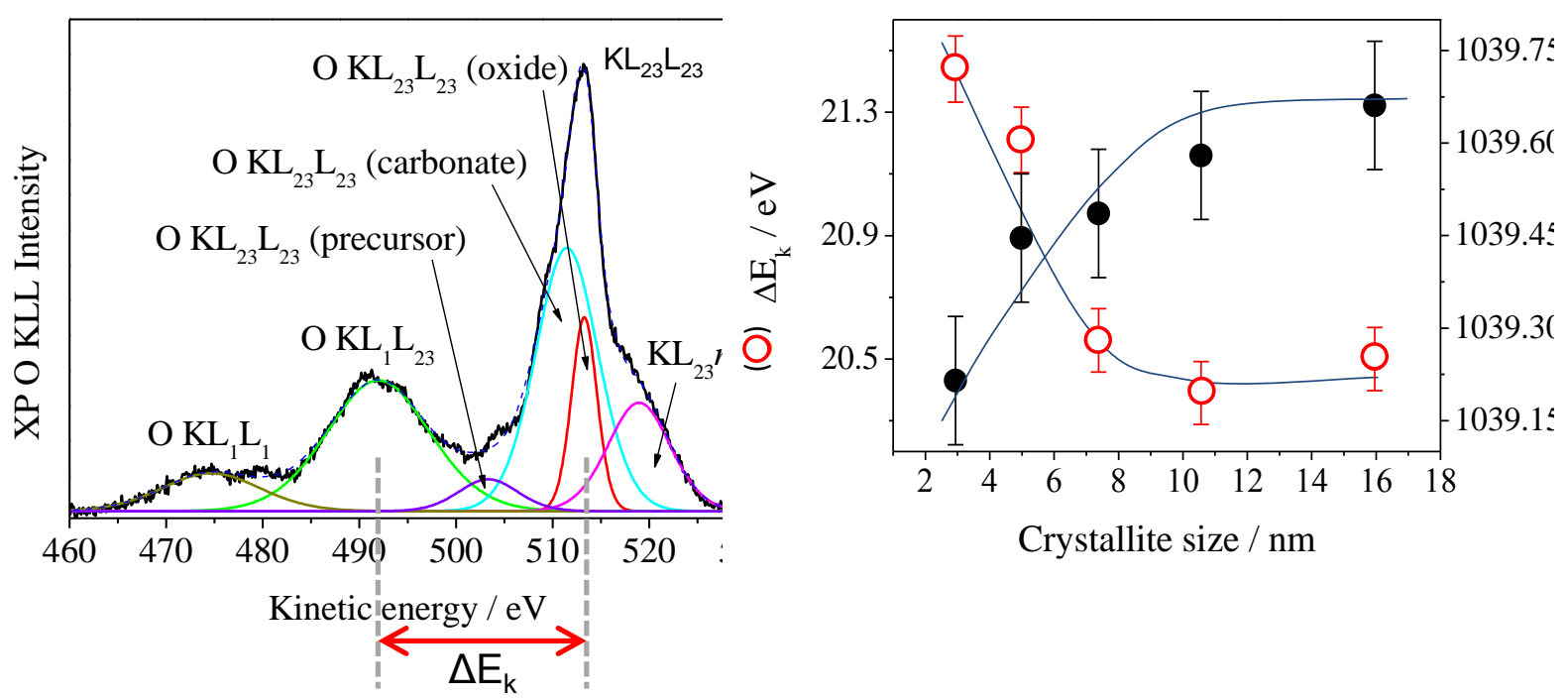

c)

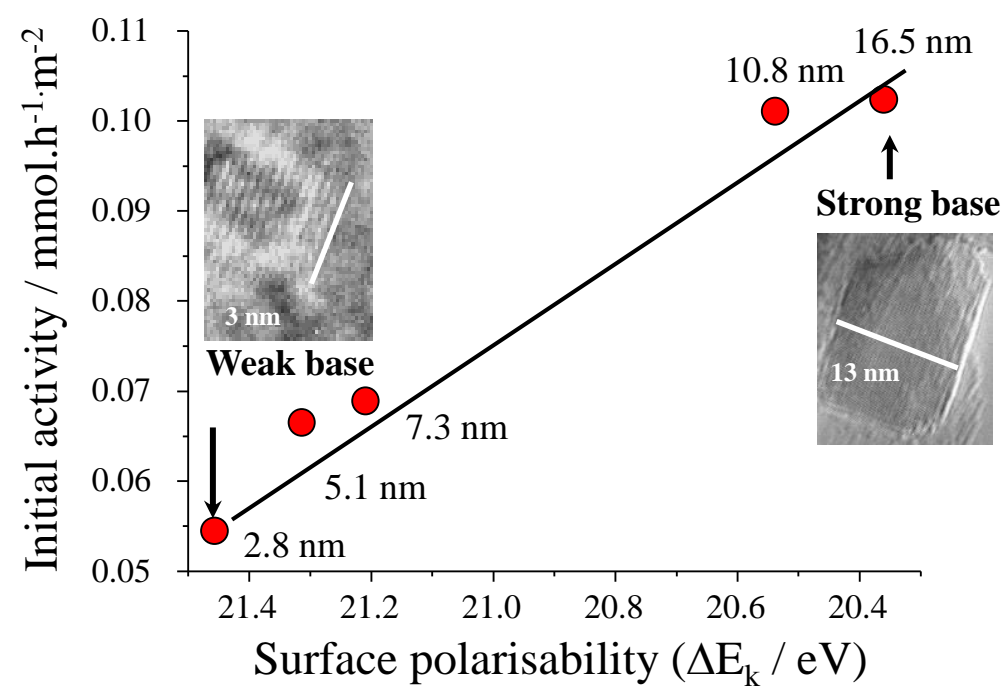

Figure 1: (a) Representative deconvoluted O KLL Auger for MgO precursor, (b) variation of Auger parameter and $\Delta \mathrm{Ek}$ with $\mathrm{MgO}$ crystallite size and (c) Correlation of activity for tributyrin transesterification with methanol and Surface polarizability. (Modified from [28] and reproduced by permission of The Royal Society of Chemistry)

\subsection{In-situ water adsorption over NanoMgO materials}

Speculation remains regarding the surface interaction between key molecular species in transesterification and $\mathrm{MgO}$, and further insight is required to provide mechanistic information relating to fatty acid methyl ester (FAME) production. Hence water, methanol and methyl acetate adsorption was subsequently explored by in-situ XPS over the parent NanoMgO and most catalytically active NanoMgO-700 materials. Water, as the simplest molecule commonly present within commercial nonfood and waste oil feedstocks, was initially investigated over and NanoMgO-700. The total surface oxygen content of NanoMgO remained largely unaffected by dosing even for water exposure up to $1 \times 10^{6} \mathrm{~L}$ (Table 2), commensurate with a $\mathrm{MgO}$ surface containing predominantly weaker base sites, unable to either dissociatively chemisorb or molecularly physisorb water within our instrumental 
detection limit. Previous work has shown that uncalcined NanoMgO exposes (100) facets and a low concentration of defect sites, hence the present observation that water does not interact with NanoMgO is consistent with single crystal studies of $\mathrm{MgO}(100)$ which reveal negligible adsorption at room temperature.[59-68] In contrast, the surface oxygen concentration of NanoMgO-700 increased monotonically with water exposure, equating to a $2 \%$ rise following $1 \times 10^{6} \mathrm{~L}$. This corroborates the hypothesis that NanoMgO-700 is the more reactive surface reflecting its higher proportion of (111) facets and low coordination defects.[27, 28]

Table 2: Surface $\mathrm{O}$ and $\mathrm{C}$ content of $\mathrm{NanoMgO}$ and NanoMgO-700 following successive exposures to $\mathrm{H}_{2} \mathrm{O}$.

\begin{tabular}{ccccc}
\hline & \multicolumn{2}{c}{ NanoMgO } & \multicolumn{2}{c}{ NanoMgO-700 } \\
& O 1s & C 1s & O 1s & C 1s \\
$\mathbf{H}_{2}$ O exposure / L & $/$ atom\% & / atom\% & / atom\% & / atom\% \\
\hline 0 & 53.0 & 19.1 & 49.8 & 15.2 \\
1 & 53.0 & 18.5 & 49.9 & 15.0 \\
10 & 52.8 & 18.9 & 50.0 & 15.3 \\
1000 & - & - & 50.7 & 14.8 \\
$1,000,000$ & 52.9 & 18.8 & 51.8 & 14.4 \\
\hline
\end{tabular}

Further evidence for changes in surface oxygen species upon $\mathrm{H}_{2} \mathrm{O}$ adsorption was apparent from the corresponding high resolution $O$ is spectra. Fig $\mathbf{2 a}$ shows representative $O$ 1s XP spectra for NanoMgO-700 after exposure to different $\mathrm{H}_{2} \mathrm{O}$ doses. All spectra were well-fitted employing three components at 528.5, 530.1 and $531.4 \mathrm{eV}$, attributed to $\mathrm{O}^{2-}, \mathrm{OH}^{-}$and $\mathrm{O}^{-}$moieties respectively.[75-77] The chemical shift of the second state is also consistent with $\mathrm{CO}_{3}{ }^{2-}$ or residual ${ }^{-\mathrm{OCH}_{3}}$ species, $[75,77]$ neither of which are expected to change following exposure to water. The $\mathrm{O}^{2-}: \mathrm{OH}^{-}$ratio decreased appreciably with increasing water exposure, consistent with the dissociative chemisorption of water over NanoMgO-700 and concomitant formation of additional surface hydroxyls. These water induced changes in $\mathrm{O}^{2-}$ and $\mathrm{OH}^{-}$species are quantified in Fig. 1b, which highlights the switchover from surface oxide to hydroxide upon dissociative water,[78] illustrated in Scheme 3; molecular water reacts with basic $\mathrm{O}^{2-}$ sites to form surface hydroxyls. 


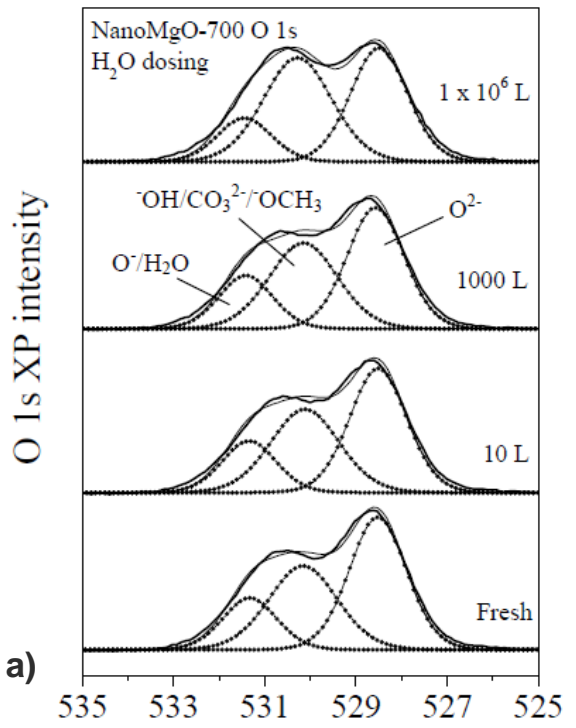

Binding energy / $\mathrm{eV}$

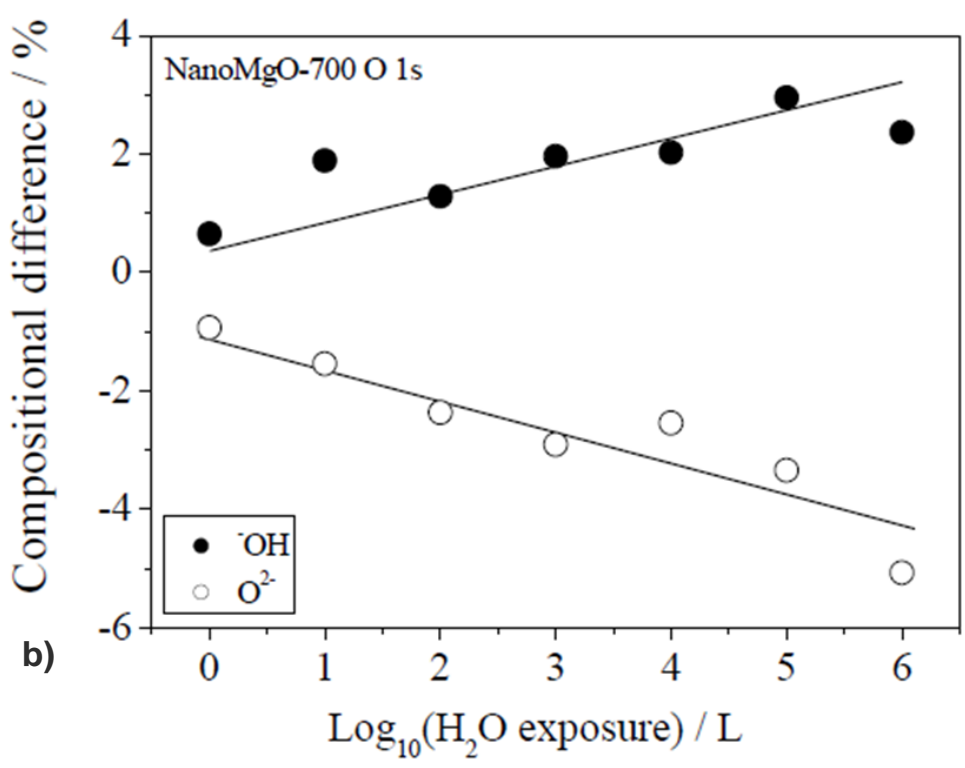

Figure 2: (a) $\mathrm{O}$ 1s spectra of NanoMgO-700 following exposure to $\mathrm{H}_{2} \mathrm{O}$, (b) difference in $\mathrm{O}$ 1s composition between fresh NanoMgO-700 and NanoMgO-700 dosed with incrementally larger $\mathrm{H}_{2} \mathrm{O}$ pressures.

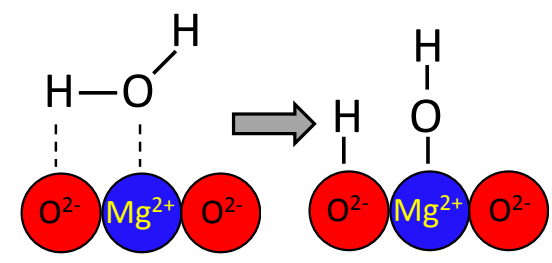

Scheme 3: Dissociation of $\mathrm{H}_{2} \mathrm{O}$ over $\mathrm{Mg}^{2+-} \mathrm{O}^{2-}$ dimers

Exposure of NanoMgO-700 to high water concentrations might therefore be expected to neutralise the $\mathrm{O}^{2-}$ Lewis base sites, themselves believed responsible for alcohol activation and subsequent TAG transesterification, and the concomitant creation of hydroxyls. However, the resulting hydroxyls may still present strong Brönsted basicity,[79] and hence water may promote a transition from Lewis to Brönsted base catalysed transesterification, enabling a high activity to be retained under reaction conditions through indirect lowering of the activation energy barriers for reaction over bare $\mathrm{Mg}^{2+-} \mathrm{O}^{2-}$ pairs within their vicinity.[80]

\subsection{In-situ methanol adsorption over NanoMgO materials}

Methanol adsorption was likewise explored over $\mathrm{NanoMgO}$ and NanoMgO-700 as it the most commonly employed alcohol to transesterify TAGs. Analogous to water adsorption, NanoMgO was unaffected by methanol exposure, with oxygen and carbon surface concentrations remaining constant (Table 3). For this uncalcined parent material, it is possible that residual methoxide groups from the methoxide precursor used in its synthesis, coupled with the intrinsically weaker surface basicity of the (100) facets which predominate over these smaller oxide nanocrystals, hinder methanol adsorption and/or dissociation, the latter in accordance with previous studies over single crystal $\mathrm{MgO}(100)$ wherein vapour pressures $>5$ Torr were required to drive molecular adsorption.[67] As seen for water, methanol 
adsorption over NanoMgO-700 induced changes in the surface composition (Table 3); the surface oxygen content increased by 1 atom\% while the carbon content increased by over 2 atom\% after the highest methanol exposure.

Table 3: Surface oxygen and carbon content of NanoMgO-700 following successive exposures to $\mathrm{CH}_{3} \mathrm{OH}$.

\begin{tabular}{ccccc}
\hline & \multicolumn{2}{c}{ NanoMgO } & \multicolumn{2}{c}{ NanoMgO-700 } \\
O 1 1s & C 1s & O 1s & C 1s \\
$\mathrm{CH}_{3}$ OH exposure & / atom\% & / atom\% & / atom\% & / atom\% \\
/ L & & & & \\
\hline 0 & 52.7 & 19.0 & 49.1 & 16.4 \\
1 & 52.7 & 18.9 & 49.6 & 17.8 \\
10 & 52.5 & 19.0 & 49.6 & 18.1 \\
1000 & - & - & 49.9 & 17.9 \\
$1,000,000$ & 52.6 & 19.0 & 49.8 & 18.8 \\
\hline
\end{tabular}

Fig. 3a shows representative C 1s XP spectra from NanoMgO-700 as a function of methanol exposure. The freshly calcined material exhibited three distinct components with binding energies of 284.0, 285.3 and $288.0 \mathrm{eV}$, assigned respectively to adventitious carbon, residual methoxide groups from the catalyst precursor, and carbonate groups.[81-84] The proportion of surface methoxide increased monotonically relative to the as calcined NanoMgO-700, even after exposure to low methanol doses (Fig. 3b).

a)

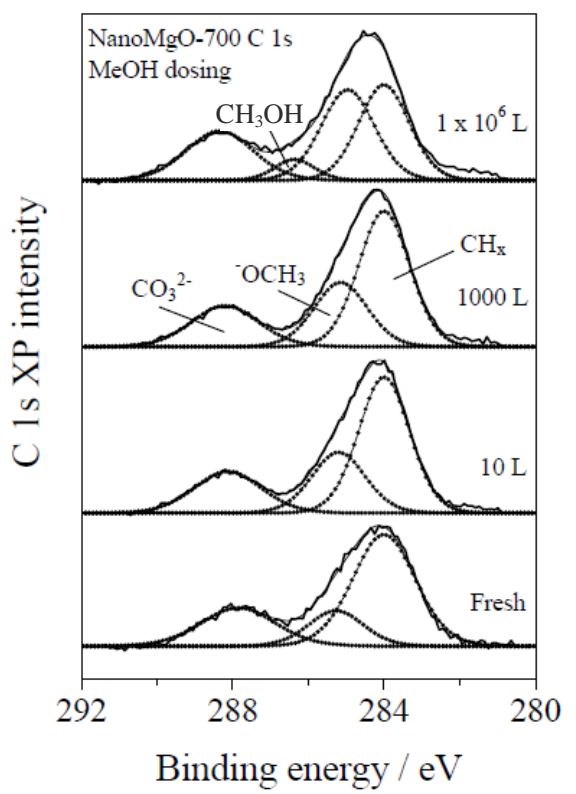

b)

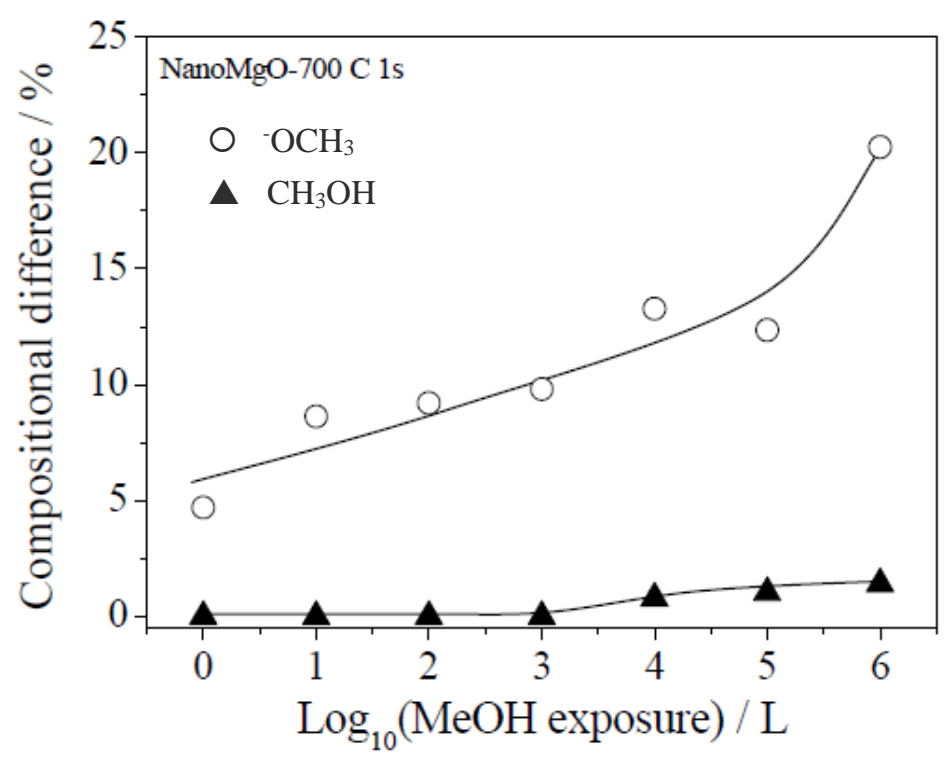

Figure 3: (a) C 1s XP spectra of NanoMgO-700 following exposure to $\mathrm{CH}_{3} \mathrm{OH}$, (b) difference in $\mathrm{C}$ 1s composition between fresh NanoMgO-700 and NanoMgO-700 dosed with incrementally larger $\mathrm{CH}_{3} \mathrm{OH}$ pressures. 
For methanol exposures $>1000 \mathrm{~L}$ a fourth $\mathrm{C}$ 1s state was observed at $286.2 \mathrm{eV}$ binding energy, indicating a different surface interaction. Ab initio calculations suggest that the strongest interaction of methanol with $\mathrm{MgO}$ occurs at oxygen vacancies in the terraces or edge sites forming $\mathrm{CH}_{3} \mathrm{O}-\mathrm{Mg}^{2+}$ and a vacancy trapped $\mathrm{H} .[85,86]$ The next strongest interaction is chemisorption over step and edge sites to form $\mathrm{O}^{2--}-\mathrm{H}-\mathrm{-O}\left(\mathrm{CH}_{3}\right)-\mathrm{Mg}^{2+}$ species in which methoxide is strongly bound to $\mathrm{Mg}^{2+}$, but the $\mathrm{O}-\mathrm{H}$ bond of methanol is not completely cleaved. Finally, over terrace sites a physisorbed $\mathrm{HOCH}_{3}$ species bridgebound between adjacent $\mathrm{Mg}^{2+} \mathrm{O}^{2-}$ pairs is predicted favoured.[86] The $\mathrm{C}$ 1s binding energy for $\mathrm{CH}_{3} \mathrm{OH}$ on Pd surfaces is reported $\sim 0.8 \mathrm{eV}$ higher than that for methoxy functions, [37] consistent with Fig. 3a, hence we propose initial dissociative adsorption of methanol over NanoMgO-700 and occupancy of defect, step and edge sites by resulting methoxy species. High methanol exposures saturate such low coordination sites, promoting a switchover to adsorption into more a weakly bound molecular state over terraces. It should be noted that for all sites dissociation to form $\mathrm{CH}_{3}$ and $\mathrm{OH}$ is energetically unfavourable.

Further insight into methanol adsorption was provided by the corresponding $\mathrm{O} 1 \mathrm{~s}$ spectra (Fig. 4a). For all methanol exposures the $\mathrm{O}$ 1s spectra exhibited three components with binding energies of 528.7, 530.5 and $531.7 \mathrm{eV}$. The low and high binding energy states are consistent with $\mathrm{O}^{2-}$ and $\mathrm{O}^{-}$species respectively,[76, 77] while the intermediate state likely reflects a superposition of contributions from $\mathrm{OH}, \mathrm{CO}_{3}^{2-},-\mathrm{OCH}_{3}$, and (at higher methanol exposures) formaldehyde moieties.[66, 75, 77, 87] Fig. 4b shows that the appearance of surface methoxide coincides with the loss of $\mathrm{O}^{2-}$ Lewis base sites, consistent with the dissociative adsorption of methanol to form methoxide and hydroxyls.

a)

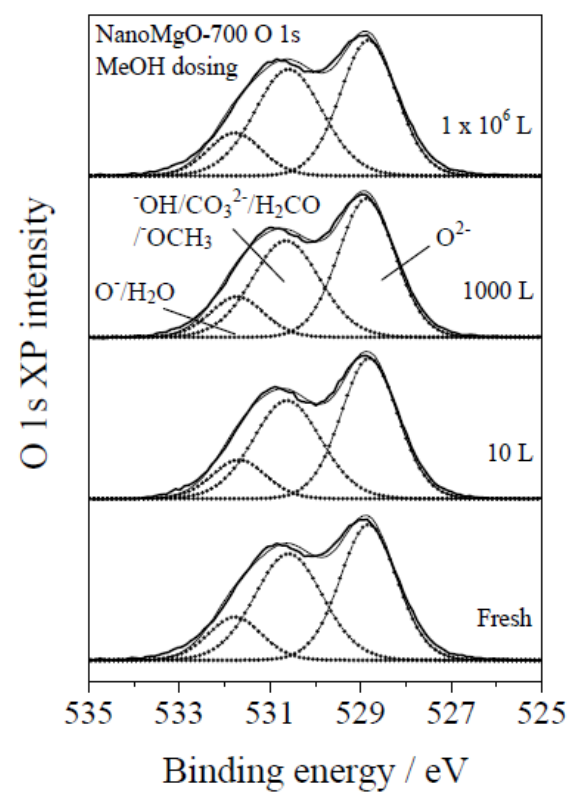

b)

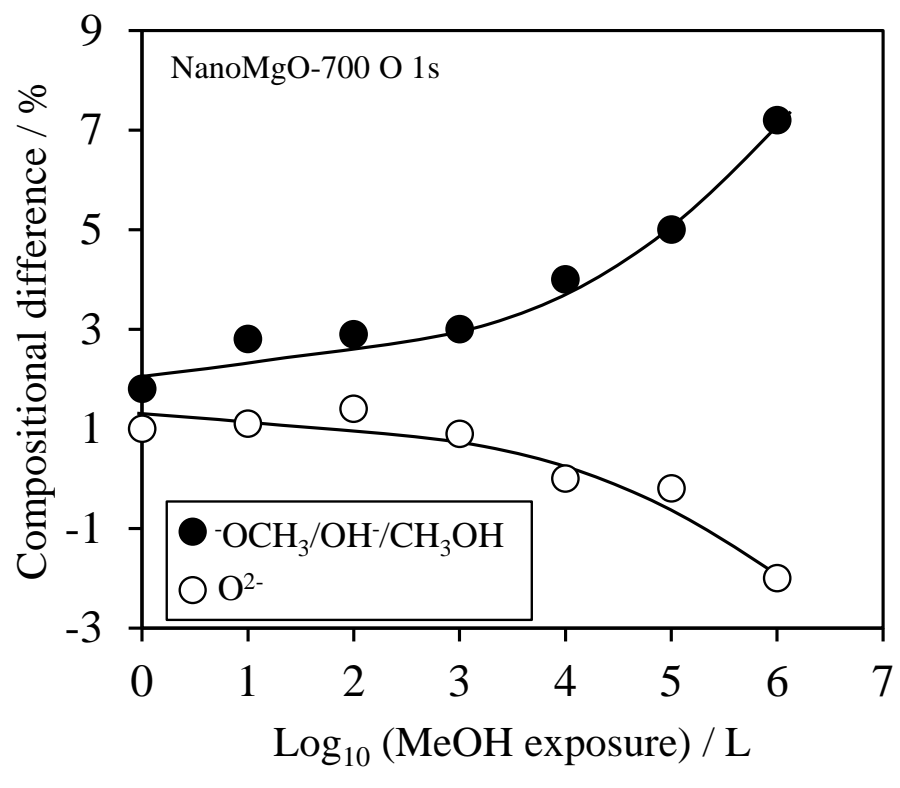

Figure 4: (a) $\mathrm{O}$ 1s XP spectra of NanoMgO-700 following exposure to $\mathrm{CH}_{3} \mathrm{OH}$, (b) difference in $\mathrm{O}$ 1s composition between fresh NanoMgO-700 and NanoMgO-700 dosed with incrementally larger $\mathrm{CH}_{3} \mathrm{OH}$ pressures. 
While methoxide formation is a key step in the $\mathrm{MgO}$ catalysed transesterification of triglycerides,[16] there is much debate as to whether this occurs over Lewis or Brönsted base sites. XPS results herein evidence a loss of Lewis basicity accompanies methoxide formation over the more defective and basic $\mathrm{MgO}(111)$ facets as previously postulated.[79] Dissociative adsorption of methanol occurs initially at edge and/or defect sites resulting in the formation of methoxide groups and hydroxide species ( $\mathrm{A}$ in Scheme 4), as previously predicted by DFT.[86] Under reaction conditions it is expected that rapid $\mathrm{MeOH}$ adsorption would lead to significant hydroxylation of $\mathrm{MgO}$ surfaces, and a catalytic mechanism dominated by the resulting Brönsted base sites generated in situ.[25] Adsorption over terrace sites favours methanol physisorption (Species B) hindering participation in the catalytic cycle. The net adsorption behaviour of $\mathrm{MeOH}$ is similar to that of $\mathrm{H}_{2} \mathrm{O}$,[88] with the surface chemistry dominated by $\mathrm{O}^{2--}-\mathrm{H}-\mathrm{O}(\mathrm{R})-\mathrm{Mg}^{2+}$ interactions (where $\mathrm{R}=\mathrm{H}$ or $\mathrm{CH}_{3}$ ).

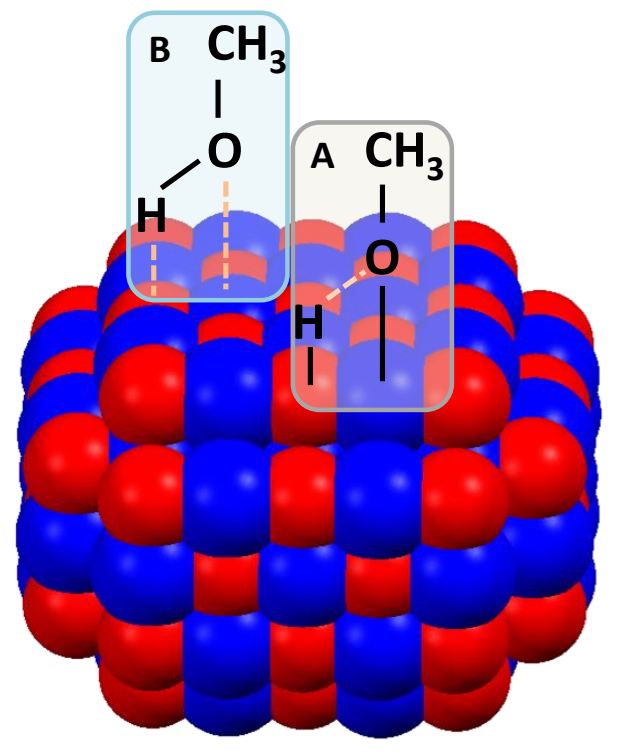

Scheme 4: Methanol adsorption over $\mathrm{MgO}$, showing A) chemisorption at $\mathrm{Mg}^{2+}-\mathrm{O}^{2-}$ dimers at edge sites and $\mathrm{B}$ ) Physisorption over terrace $\mathrm{Mg}^{2+}-\mathrm{O}^{2-}$ sites.

\subsection{In-situ methyl acetate adsorption over Nano-MgO}

While biodiesel synthesis involves the activation of triglycerides over MgO surfaces, the critical interaction with the ester product [31] has been neglected; surprisingly little is known regarding the adsorption mode of esters over $\mathrm{MgO}$, which will likely coordinate through a methoxide function, hence methyl acetate was selected as a suitably volatile, model FAME. Table 4 summarises the surface compositional changes accompanying methyl acetate adsorption over NanoMgO and NanoMgO-700. Akin to water and methanol, methyl acetate did not adsorb to any detectable degree over the NanoMgO, but did adsorb over the more basic NanoMgO-700.

Table 4: Surface oxygen and carbon content of NanoMgO-700 following successive exposure to $\mathrm{CH}_{3} \mathrm{OAc}$.

\begin{tabular}{ccccc}
\hline & \multicolumn{2}{c}{ NanoMgO } & \multicolumn{2}{c}{ NanoMgO-700 } \\
& $01 \mathrm{~s}$ & $\mathrm{C}$ 1s & $01 \mathrm{~s}$ & $\mathrm{C} 1 \mathrm{~s}$ \\
$\mathrm{CH}_{3} \mathrm{OAc}$ e exposure / $\mathrm{L}$ & $/$ atom $\%$ & $/$ atom $\%$ & $/$ atom $\%$ & $/$ atom $\%$ \\
\hline
\end{tabular}




\begin{tabular}{ccccc}
\hline 0 & 53.7 & 18.9 & 49.2 & 17.0 \\
1 & 54.1 & 19.0 & 49.4 & 19.7 \\
10 & 53.9 & 18.5 & 49.6 & 18.9 \\
1000 & - & - & 50.4 & 18.9 \\
$1,000,000$ & 53.3 & 18.1 & 51.3 & 19.0 \\
\hline
\end{tabular}

Methyl acetate $\left(\mathrm{CH}_{3} \mathrm{O}(\mathrm{O}=) \mathrm{CCH}_{3}\right)$ possesses three unique carbon environments: $\mathrm{CH}_{3} \mathrm{O}-, \mathrm{O}(\mathrm{O}=) \mathbf{C}$ - and $-\mathrm{CH}_{3}$. Fig. 5 shows the evolution of $\mathrm{C}$ 1s spectra following exposure of NanoMgO-700 to MeOAc, which reveal the anticipated emergence of $\mathrm{CH}_{\mathrm{x}}$ and $\mathrm{CO}_{3} / \mathrm{COO}^{-}$states at 284.0 and $288.2 \mathrm{eV}$ respectively at low ester exposures, but concomitant diminution of the $\mathrm{CH}_{3} \mathrm{O}$ - component. This latter observation is catalytically significant, as it suggests that low concentrations of methyl acetate (i.e. desired FAME product) are dissociatively adsorbed in the presence of $\mathrm{O}^{2-}$ strong base sites over NanoMgO-700. Recent calculations on ethyl acetate adsorption on $\mathrm{MgO}(110)$ facets and defect sites suggest binding occurs via a strong Lewis acid-base adduct,[88] with the ester carbonyl coordinating through its oxygen to unsaturated $\mathrm{Mg}^{2+}$ cations in defective surfaces, as shown in Scheme 5a. Subsequent $\mathrm{CH}$ dissociation catalysed by $\mathrm{O}^{2-}$ sites in the vicinity is energetically favourable, and drives the adsorption process (Scheme $5 b$ ). CH cleavage is also supported by experimental and DFT studies that show calcined MgO can abstract protons from carbonyls[32] and weakly acidic organic molecules with $\mathrm{pK}_{\mathrm{a}}$ values as high as 40.[89] Since methyl acetate has a $\mathrm{pK}_{\mathrm{a}}$ around 25, it is plausible that the $\mathrm{O}^{2-}$ strong base sites on NanoMgO-700 could abstract protons from the reactively-formed ester products of transesterification, resulting in the formation of $\mathrm{CH}_{2}$ bound species (Scheme 6).[66] While the formation of such species is thermodynamically feasible in the gas phase, and could account for the present XPS observations, the operation of such routes in the liquid phase is unproven. An alternative decomposition pathway could occur via surface $-\mathrm{OH}$ catalysed hydrolysis of adsorbed esters to generate surface acetate groups.[34] However, spectral contributions from such acetate groups would likely overlap with the $C$ 1s state observed at $294 \mathrm{eV}$ over nanoMgO-700,[76, 84] originating from surface carbonate,[66, 83] and hence cannot be unequivocally revoked. 


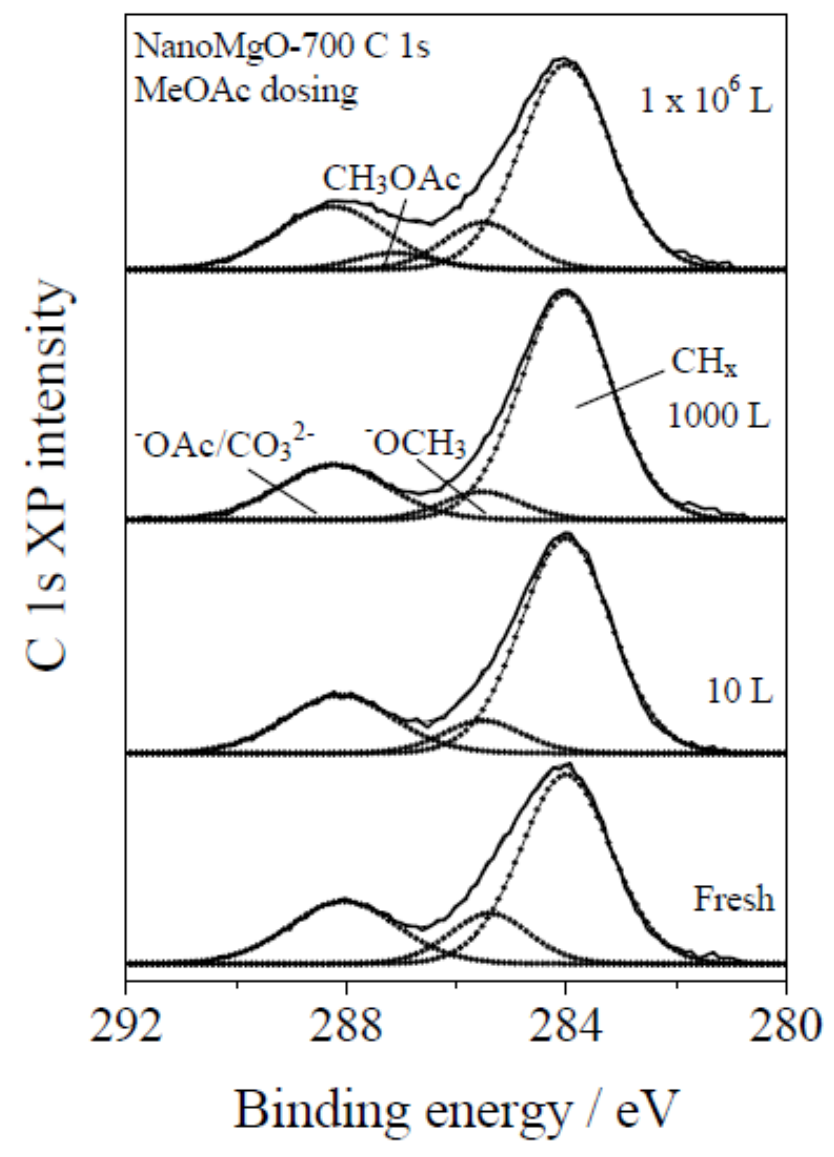

Figure 5: $\mathrm{C}$ 1s XP spectra of NanoMgO-700 following exposure to $\mathrm{CH}_{3} \mathrm{OAc}$
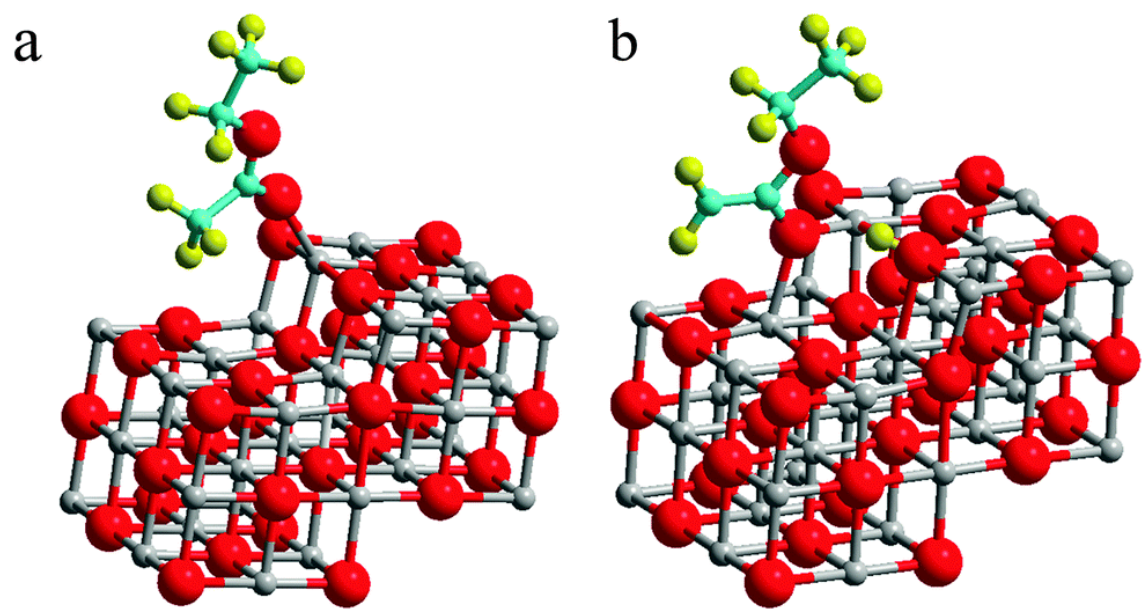

Scheme 5: DFT optimized structures of the ester molecule adsorbed on a $\mathrm{MgO}(100)$ step, before and after methyl group deprotonation. (a) protonated ester, (b) deprotonated ester. Reproduced from Ref. [88] with permission from the PCCP Owner Societies. 


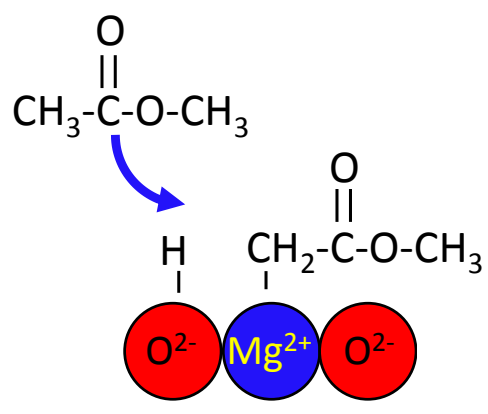

Scheme 6: Potential route to methyl acetate dissociation over NanoMgO surface.[33]

Higher ester exposures up to $1 \times 10^{6} \mathrm{~L}$ gave rise to features at 285.5 and $287.2 \mathrm{eV}$, attributed to $-\mathrm{OCH}_{3}$ and $\mathrm{O}-\mathrm{C}(=\mathrm{O})$, consistent with molecular adsorption of methyl acetate.[90] It is likely that saturation of strong base sites favours molecular adsorption of methyl acetate at more weakly basic terrace sites as for methanol. Support for the preceding adsorption mechanism is evidenced from the corresponding $O$ 1s spectra in Fig. 6, which shows three states, corresponding to $\mathrm{O}^{2-}, \mathrm{O}^{-}$and $-\mathrm{OH} / \mathrm{CO}_{3}{ }^{2-} / \mathrm{residual}{ }^{-} \mathrm{OCH}_{3}$ as previously discussed. Acetate ions and molecularly adsorbed methyl acetate, which appears at higher ester exposures, are indistinguishable from the other components having binding energies that overlap with the $530.5 \mathrm{eV}$ state.[90] While it is not practicable to fit so many components to a single feature, it is clear that the intensity of the $530.5 \mathrm{eV}$ envelope increases with methyl acetate exposure relative to the $\mathrm{O}^{2-}$ state, consistent with $\mathrm{C}-\mathrm{H}$ cleavage and accompanying conversion of surface $\mathrm{O}^{2-} \rightarrow$ $-\mathrm{OH}$. As for water and methanol adsorption, calcined nanocrystalline $\mathrm{MgO}$ interacts more strongly with methyl acetate than as-synthesised, smaller and less basic NanoMgO. The loss of $\mathrm{O}^{2-}$ sites following ester adsorption[27, 28] implies that strong base sites could hinder the desorption of reactively-formed FAMEs and hence self-poison the transesterification reaction.

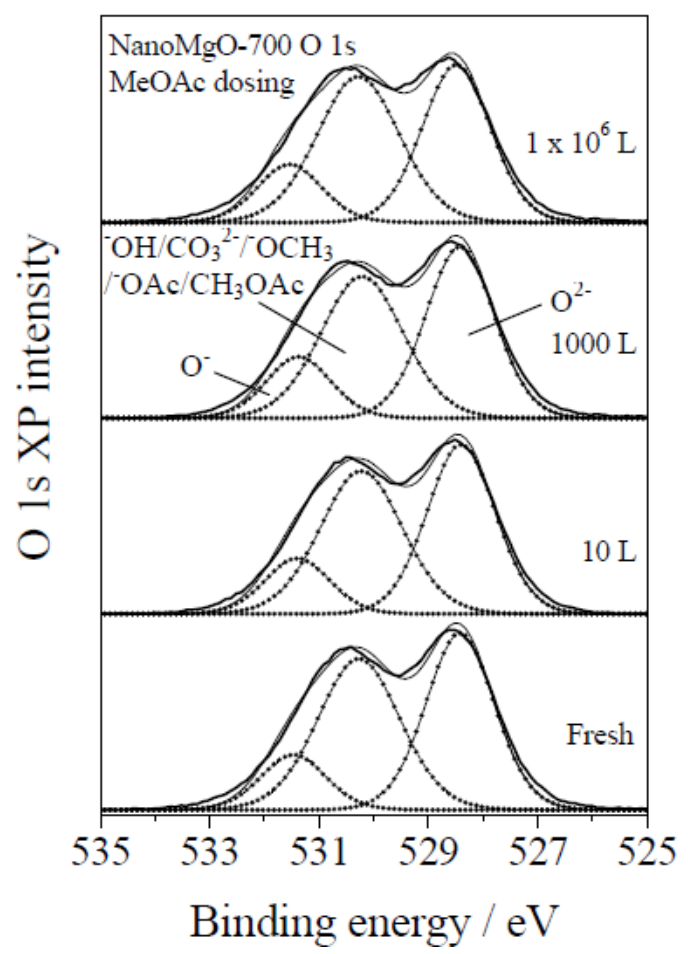


Figure 6: $\mathrm{O}$ 1s XP spectra of NanoMgO-700 following exposure to $\mathrm{CH}_{3} \mathrm{OAc}$.

\subsection{Analysis of spent nanocrystalline $\mathrm{MgO}$}

The preceding observations over freshly calcined NanoMgO-700 were finally compared with the surface of a spent NanoMgO-700 sample following the liquid phase transesterification of tributyrin with methanol. Fig. 7 shows the resultant $C$ 1s XP spectrum which shows a large increase in intensity of the $284.0 \mathrm{eV}$ state arising from the hydrocarbon backbone of adsorbed butyrate. A new $285.4 \mathrm{eV}$ state is also apparent, likely associated with surface methoxide and alkoxide groups due to the dissociative chemisorption of methanol and glycerol. Another new $287.7 \mathrm{eV}$ state was also observed in the spent sample, possibly due to the presence of acyl or carboxylate groups from adsorbed methyl butyrate and unreacted triglycerides.[91].[76] There was no evidence for surface carbonate at $288.9 \mathrm{eV}$ in the spent catalyst. The accumulation of carbon-containing species on the $\mathrm{MgO}$ surface, probably resulting from reaction with strongly basic $\mathrm{O}^{2-}$ active sites, would appear the prime candidate for experimentally observed on-stream deactivation of NanoMgO.[28]

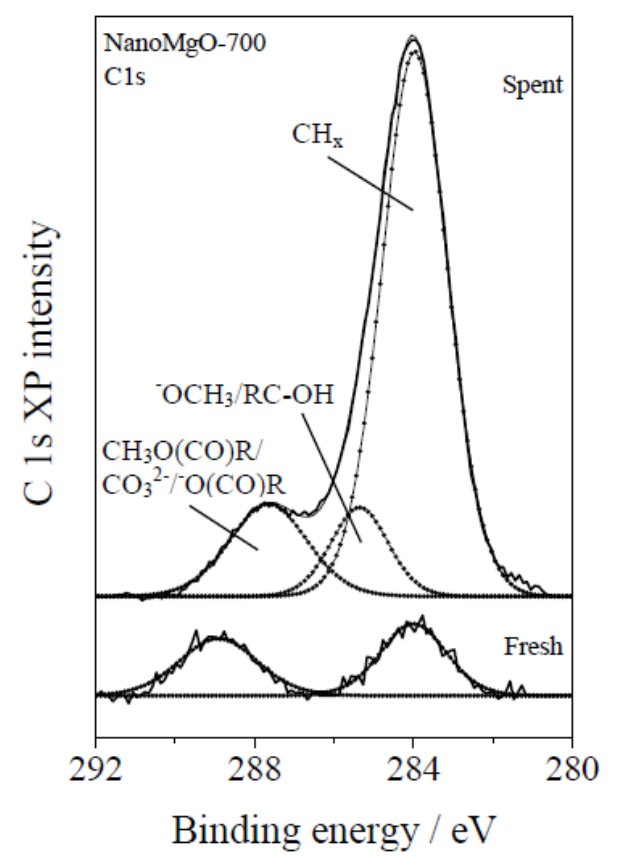

Figure 7: C 1s XP spectra of fresh and spent NanoMgO-700, following tributyrin transesterification

\section{Conclusions}

In situ XPS of water, methanol and methyl acetate adsorption over as-synthesised and calcined MgO nanocatalysts was undertaken in order to provide insight into the surface interaction of each component during the production of fatty acid methyl esters (biodiesel) via the transesterification of triglycerides 
with methanol. High temperature calcined NanoMgO-700 adsorbed all three species more readily than the parent material due to the higher density of electron-rich (111) and (110) facets exposed over the larger crystallites. Water and methanol chemisorb over the NanoMgO-700 through the conversion of surface $\mathrm{O}^{2-}$ sites to $\mathrm{OH}^{-}$and coincident creation of $\mathrm{Mg}-\mathrm{OH}$ or $\mathrm{Mg}-\mathrm{OCH}_{3}$ moieties respectively. In light of literature DFT calculations, a model is proposed in which the dissociative chemisorption of methanol occurs preferentially over defect and edge sites over NanoMgO-700, with higher methanol coverages resulting in physisorption over weakly basic (100) facets. Methyl acetate undergoes more complex surface chemistry over NanoMgO-700, with $\mathrm{C}-\mathrm{H}$ dissociation and ester cleavage forming surface hydroxyl and acetate species even at extremely low coverages, indicative of preferential adsorption at defects. C 1s XP spectra show that spent NanoMgO-700 catalysts recovered after the liquid phase transesterification of tributyrin with methanol exhibit significant surface $\mathrm{CHx}$ and $\mathrm{COO}$ - species accumulation, suggesting that ester hydrolysis plays a key factor in the deactivation of $\mathrm{MgO}$ catalysts for biodiesel production.

\section{Acknowledgements}

Financial support from the EPSRC under EP/F063423/1 and EP/K000616/1 and for the provision of Leadership Fellowship to AFL (EP/G007594/4) is acknowledged. KW is grateful to the Royal Society for the award of an Industry Fellowship (IF100206).

\section{References}

[1] C.C. Authority, Reducing Australia's Greenhouse Gas Emissions -Targets and Progress Review Draft Report, in, Commonwealth of Australia, 2013.

[2] C.C. Secretariat, THE CRITICAL DECADE 2013 Climate change science, risks and responses, in, Commonwealth of Australia, 2013.

[3] I.E. Agency, Prospect of limiting the global increase in temperature to $2^{\circ} \mathrm{C}$ is getting bleaker, in, 2011.

[4] I.E. Agency, Redrawing the Energy Climate Map, in, 2013.

[5] T.P. Vispute, H. Zhang, A. Sanna, R. Xiao, G.W. Huber, Renewable Chemical Commodity Feedstocks from Integrated Catalytic Processing of Pyrolysis Oils, Science, 330 (2010) 1222-1227.

[6] P.M. Mortensen, J.D. Grunwaldt, P.A. Jensen, K.G. Knudsen, A.D. Jensen, A review of catalytic upgrading of bio-oil to engine fuels, Applied Catalysis A: General, 407 (2011) 1-19.

[7] R. Luque, L. Herrero-Davila, J.M. Campelo, J.H. Clark, J.M. Hidalgo, D. Luna, J.M. Marinas, A.A. Romero, Biofuels: a technological perspective, Energy \& Environmental Science, 1 (2008) 542-564.

[8] C.S.K. Lin, L.A. Pfaltzgraff, L. Herrero-Davila, E.B. Mubofu, S. Abderrahim, J.H. Clark, A.A. Koutinas, N. Kopsahelis, K. Stamatelatou, F. Dickson, S. Thankappan, Z. Mohamed, R. Brocklesby, R. Luque, Food waste as a valuable resource for the production of chemicals, materials and fuels. Current situation and global perspective, Energy \& Environmental Science, 6 (2013) 426-464.

[9] A. Demirbas, Importance of biodiesel as transportation fuel, Energy Policy, 35 (2007) 4661-4670.

[10] M.J. Climent, A. Corma, S. Iborra, A. Velty, Activated hydrotalcites as catalysts for the synthesis of chalcones of pharmaceutical interest, Journal of Catalysis, 221 (2004) 474-482.

[11] U. Constantino, F. Marmottini, M. Nocchetti, R. Vivani, New synthetic routes to hydrotalcite-like compounds - characterisation and properties of the obtained materials, European Journal of Inorganic Chemistry, (1998) 1439-1446.

[12] K. Narasimharao, A. Lee, K. Wilson, Catalysts in Production of Biodiesel: A Review, Journal of Biobased Materials and Bioenergy, 1 (2007) 19-30. 
[13] M.R. Othman, Z. Helwani, Martunus, W.J.N. Fernando, Synthetic hydrotalcites from different routes and their application as catalysts and gas adsorbents: a review, Applied Organometallic Chemistry, 23 (2009) 335-346.

[14] Y. Liu, E. Lotero, J.G. Goodwin, X. Mo, Transesterification of poultry fat with methanol using Mg-Al hydrotalcite derived catalysts, Applied Catalysis A: General, 33 (2007) 138-148.

[15] G. Knothe, Biodiesel: Current Trends and Properties, Topics in Catalysis, 53 (2010) 714-720.

[16] F. Ma, M.A. Hanna, Biodiesel production: a review, Bioresource Technology, 70 (1999) 1-15.

[17] E. Lotero, Y. Liu, D.E. Lopez, K. Suwannakarn, D.A. Bruce, J.G. Goodwin, Synthesis of Biodiesel via Acid Catalysis, Industrial \& Engineering Chemistry Research, 44 (2005) 5353-5363.

[18] V.C. J.Sheehan, J.Duffield, M.Graboski, H.Shapouri, 'An Overview of Biodiesel and Petroleum Diesel Life Cycles', National Renewable Energy Laboratory, U.S. Department of Energy, NREL/TP580-24772, 1998.

[19] J.M. Thomas, The societal significance of catalysis and the growing practical importance of singlesite heterogeneous catalysts, Proceedings of the Royal Society A: Mathematical, Physical and Engineering Science, 468 (2012) 1884-1903.

[20] G.A. Somorjai, H. Frei, J.Y. Park, Advancing the Frontiers in Nanocatalysis, Biointerfaces, and Renewable Energy Conversion by Innovations of Surface Techniques, Journal of the American Chemical Society, 131 (2009) 16589-16605.

[21] R. Luque, J.C. Lovett, B. Datta, J. Clancy, J.M. Campelo, A.A. Romero, Biodiesel as feasible petrol fuel replacement: a multidisciplinary overview, Energy \& Environmental Science, 3 (2010) 1706-1721.

[22] J.-P. Dacquin, A.F. Lee, K. Wilson, Chapter 16 Heterogeneous Catalysts for Biodiesel Production, in: Thermochemical Conversion of Biomass to Liquid Fuels and Chemicals, The Royal Society of Chemistry, 2010, pp. 416-434.

[23] K. Wilson, A.F. Lee, Rational design of heterogeneous catalysts for biodiesel synthesis, Catalysis Science \& Technology, 2 (2012) 884-897.

[24] V.C. Eze, A.N. Phan, C. Pirez, A.P. Harvey, A.F. Lee, K. Wilson, Heterogeneous catalysis in an oscillatory baffled flow reactor, Catalysis Science \& Technology, 3 (2013) 2373-2379.

[25] U. Schuchardt, R. Sercheli, R.M. Vargas, Transesterification of vegetable oils: a review, Journal of the Brazilian Chemical Society, 9 (1998) 199-210.

[26] J.P. Guthrie, Concerted mechanism for alcoholysis of esters: an examination of the requirements, Journal of the American Chemical Society, 113 (1991) 3941-3949.

[27] J.M. Montero, D.R. Brown, P.L. Gai, A.F. Lee, K. Wilson, In situ studies of structure-reactivity relations in biodiesel synthesis over nanocrystalline MgO, Chemical Engineering Journal, 161 (2010) 332-339.

[28] J.M. Montero, P. Gai, K. Wilson, A.F. Lee, Structure-sensitive biodiesel synthesis over MgO nanocrystals, Green chemistry, 11 (2009) 265-268.

[29] M. Fernández-García, A. Martínez-Arias, J.C. Hanson, J.A. Rodriguez, Nanostructured Oxides in Chemistry: Characterization and Properties, Chemical Reviews, 104 (2004) 4063-4104.

[30] J.A. Farmer, C.T. Campbell, L. Xu, G. Henkelman, Defect sites and their distributions on MgO (100) by Li and Ca adsorption calorimetry, Journal of the American Chemical Society, 131 (2009) 3098-3103. [31] J. Goniakowski, C. Noguera, Atomic and electronic structure of steps and kinks on $\mathrm{MgO}(100)$ and $\mathrm{MgO}(110)$, Surface Science, 340 (1995) 191-204.

[32] G. Pacchioni, Ab initio theory of point defects in oxide materials: structure, properties, chemical reactivity, Solid State Sciences, 2 (2000) 161-179.

[33] G. Arzamendi, E. Arguiñarena, I. Campo, S. Zabala, L.M. Gandía, Alkaline and alkaline-earth metals compounds as catalysts for the methanolysis of sunflower oil, Catalysis Today, 133-135 (2008) 305-313.

[34] M. Verziu, B. Cojocaru, J. Hu, R. Richards, C. Ciuculescu, P. Filip, V.I. Parvulescu, Sunflower and rapeseed oil transesterification to biodiesel over different nanocrystalline $\mathrm{MgO}$ catalysts, Green Chemistry, 10 (2008) 373-381.

[35] A. Corma, S. Iborra, S. Miquel, J. Primo, Catalysts for the Production of Fine Chemicals: Production of Food Emulsifiers, Monoglycerides, by Glycerolysis of Fats with Solid Base Catalysts, Journal of Catalysis, 173 (1998) 315-321.

[36] G.R. Peterson, W.P. Scarrah, Rapeseed oil transesterification by heterogeneous catalysis, J Am Oil Chem Soc, 61 (1984) 1593-1597.

[37] K. Zhu, J. Hu, C. Kübel, R. Richards, Efficient Preparation and Catalytic Activity of MgO(111) Nanosheets, Angewandte Chemie International Edition, 45 (2006) 7277-7281. 
[38] T. Selvamani, T. Yagyu, S. Kawasaki, I. Mukhopadhyay, Easy and effective synthesis of micrometer-sized rectangular MgO sheets with very high catalytic activity, Catalysis Communications, 11 (2010) 537-541.

[39] S. Utamapanya, K.J. Klabunde, J.R. Schlup, Nanoscale metal oxide particles/clusters as chemical reagents. Synthesis and properties of ultrahigh surface area magnesium hydroxide and magnesium oxide, Chemistry of Materials, 3 (1991) 175-181.

[40] D.G. Cantrell, L.J. Gillie, A.F. Lee, K. Wilson, Structure-reactivity correlations in MgAl hydrotalcite catalysts for biodiesel synthesis, Applied Catalysis A: General, 287 (2005) 183-190.

[41] A.F. Lee, D.E. Gawthrope, N.J. Hart, K. Wilson, A fast XPS study of the surface chemistry of ethanol over Pt $\{111\}$, Surface science, 548 (2004) 200-208.

[42] J. Yates, M. Alvey, M. Dresser, M. Henderson, M. Kiskinova, R. Ramsier, A. Szabo, Direct observation of chemical bond dynamics on surfaces, Science, 255 (1992) 1397-1403.

[43] F. Zaera, D. Godbey, G. Somorjai, Methylcyclopentane conversion over platinum single crystal surfaces: Evidence for the cyclic mechanism of $<\mathrm{i}>\mathrm{n}</ \mathrm{i}>-$ hexane isomerization, Journal of Catalysis, 101 (1986) 73-80.

[44] C. Papp, B. Tränkenschuh, R. Streber, T. Fuhrmann, R. Denecke, H.-P. Steinrück, Influence of steps on the adsorption of methane on platinum surfaces, The Journal of Physical Chemistry C, 111 (2007) 2177-2184.

[45] A.F. Lee, S.F. Hackett, G.J. Hutchings, S. Lizzit, J. Naughton, K. Wilson, In situ X-ray studies of crotyl alcohol selective oxidation over Au/Pd (111) surface alloys, Catalysis Today, 145 (2009) 251257.

[46] M. Neurock, Perspectives on the first principles elucidation and the design of active sites, Journal of Catalysis, 216 (2003) 73-88.

[47] H. Idriss, M.A. Barteau, Active sites on oxides: from single crystals to catalysts, Advances in Catalysis, 45 (2000) 261-331.

[48] F. Kitamura, M. Takahashi, M. Ito, Carbon monoxide adsorption on platinum (111) single-crystal electrode surface studied by infrared reflection-absorption spectroscopy, Surface Science, 223 (1989) 493-508.

[49] L. Shorthouse, Y. Jugnet, J. Bertolini, In situ infrared spectroscopy applied to catalytic reactions on metal single crystals, Catalysis today, 70 (2001) 33-42.

[50] H. Conrad, G. Ertl, E. Latta, Adsorption of hydrogen on palladium single crystal surfaces, Surface Science, 41 (1974) 435-446.

[51] J. Bertolini, B. Tardy, Vibrational EELS studies of CO chemisorption on clean and carbided (111),(100) and (110) nickel surfaces, Surface Science, 102 (1981) 131-150.

[52] M. Chesters, D. Lennon, The adsorption of carbon tetrachloride on Ni (110): an EELS, AES and LEED study, Surface science, 426 (1999) 92-105.

[53] A. Carley, S. Jackson, M. Roberts, J. O'Shea, Alkali metal reactions with Ni (110)-O and NiO (100) surfaces, Surface science, 454 (2000) 141-146.

[54] J. Stöhr, F. Sette, A.L. Johnson, Near-edge X-ray-absorption fine-structure studies of chemisorbed hydrocarbons: bond lengths with a ruler, Physical review letters, 53 (1984) 1684.

[55] K. Brandt, M.E. Chiu, D.J. Watson, M.S. Tikhov, R.M. Lambert, Chemoselective catalytic hydrogenation of acrolein on $\mathrm{Ag}$ (111): Effect of molecular orientation on reaction selectivity, Journal of the American Chemical Society, 131 (2009) 17286-17290.

[56] K. Queeney, C. Arumainayagam, M. Weldon, C. Friend, M. Blumberg, Differential reactivity and structure of mono-and dialkoxides: the reactions of ethylene glycol on Mo (110), Journal of the American Chemical Society, 118 (1996) 3896-3904.

[57] C.T. Campbell, Ultrathin metal films and particles on oxide surfaces: structural, electronic and chemisorptive properties, Surface Science Reports, 27 (1997) 1-111.

[58] H. Idriss, Surface reactions of uranium oxide powder, thin films and single crystals, Surface Science Reports, 65 (2010) 67-109.

[59] G. Pacchioni, J.M. Ricart, F. Illas, Ab initio cluster model calculations on the chemisorption of $\mathrm{CO} 2$ and $\mathrm{SO} 2$ probe molecules on $\mathrm{MgO}$ and $\mathrm{CaO}(100)$ surfaces. A theoretical measure of oxide basicity, Journal of the American Chemical Society, 116 (1994) 10152-10158.

[60] X. Peng, M. Barteau, Acid-base reactions on model MgO surfaces, Catalysis letters, 12 (1992) 245253.

[61] Y. Wang, T.N. Truong, Theoretical study of adsorption of water dimer on the perfect MgO (100) surface: Molecular adsorption versus dissociative chemisorption, The Journal of Physical Chemistry B, 108 (2004) 3289-3294. 
[62] J.H. Lee, J.H. Eun, S.G. Kim, S.Y. Park, M.J. Lee, H.J. Kim, Hydration behavior of MgO single crystals and thin films, Journal of materials research, 18 (2003) 2895-2903.

[63] H. Huang, X. Jiang, Z. Zou, W. Chin, G. Xu, W. Dai, K. Fan, J. Deng, Potassium adsorption and reaction with water on $\mathrm{MgO}$ (100), Surface science, 412 (1998) 555-561.

[64] C. Scamehorn, N. Harrison, M. McCarthy, Water chemistry on surface defect sites: Chemidissociation versus physisorption on MgO (001), The Journal of chemical physics, 101 (1994) 1547-1554.

[65] M. Stirniman, C. Huang, R.S. Smith, S. Joyce, B.D. Kay, The adsorption and desorption of water on single crystal MgO (100): The role of surface defects, The Journal of chemical physics, 105 (1996) 1295-1298.

[66] H. Onishi, C. Egawa, T. Aruga, Y. Iwasawa, Adsorption of $\mathrm{Na}$ atoms and oxygen-containing molecules on MgO (100) and (111) surfaces, Surface Science, 191 (1987) 479-491.

[67] J. Rudberg, M. Foster, Adsorption of methanol on the MgO (100) surface: An infrared study at room temperature, The Journal of Physical Chemistry B, 108 (2004) 18311-18317.

[68] X. Peng, M.A. Barteau, Adsorption of formaldehyde on model magnesia surfaces: evidence for the Cannizzaro reaction, Langmuir, 5 (1989) 1051-1056.

[69] S.S. Perry, P.B. Merrill, Preparation and characterization of MgO (100) surfaces, Surface science, 383 (1997) 268-276.

[70] J. Ciston, A. Subramanian, L. Marks, Water-driven structural evolution of the polar MgO (111) surface: An integrated experimental and theoretical approach, Physical Review B, 79 (2009) 085421.

[71] V.E. Henrich, Thermal faceting of (110) and (111) surfaces of MgO, Surface Science, 57 (1976) 385-392.

[72] R. Plass, J. Feller, M. Gajdardziska-Josifovska, Morphology of MgO (111) surfaces: artifacts associated with the faceting of polar oxide surfaces into neutral surfaces, Surface science, 414 (1998) 26-37.

[73] P.L. Gai, J.M. Montero, A.F. Lee, K. Wilson, E.D. Boyes, In situ aberration corrected-transmission electron microscopy of magnesium oxide nanocatalysts for biodiesels, Catalysis letters, 132 (2009) 182-188.

[74] J.A.D. Matthew, S. Parker, Correlations between the Auger parameters of oxygen and metal atoms in oxygen-containing compounds, Journal of Electron Spectroscopy and Related Phenomena, 85 (1997) 175-178.

[75] D.E. Haycock, M. Kasrai, C.J. Nicholls, D.S. Urch, The electronic structure of magnesium hydroxide (brucite) using X-ray emission, X-ray photoelectron, and auger spectroscopy, Journal of the Chemical Society, Dalton Transactions, (1978) 1791-1796.

[76] R. Jerome, P. Teyssie, J. Pireaux, J. Verbist, Surface analysis of polymers end-capped with metal carboxylates using x-ray photoelectron spectroscopy, Applied surface science, 27 (1986) 93-105.

[77] T. Karasuda, K.-i. Aika, Characterization of Electron Deficient Oxide Ion of Heat Treated MgO for Activation of Methane, Bulletin of the Chemical Society of Japan, 71 (1998) 1999-2003.

[78] C. Chizallet, G. Costentin, M. Che, F. Delbecq, P. Sautet, Revisiting acido-basicity of the MgO surface by periodic density functional theory calculations: Role of surface topology and ion coordination on water dissociation, The Journal of Physical Chemistry B, 110 (2006) 15878-15886.

[79] K. Tanabe, M. Misono, H. Hattori, Y. Ono, New solid acids and bases: their catalytic properties, Elsevier, 1990.

[80] H. Petitjean, H. Guesmi, H. Lauron-Pernot, G. Costentin, D. Loffreda, P. Sautet, F. Delbecq, How Surface Hydroxyls Enhance MgO Reactivity in Basic Catalysis: The Case of Methylbutynol Conversion, ACS Catalysis, 4 (2014) 4004-4014.

[81] N. Freyer, G. Pirug, H. Bonzel, C (1s) spectroscopy of hydrocarbons adsorbed on Pt (111), Surface Science, 126 (1983) 487-494.

[82] H. Jensen, A. Soloviev, Z. Li, E.G. Søgaard, XPS and FTIR investigation of the surface properties of different prepared titania nano-powders, Applied Surface Science, 246 (2005) 239-249.

[83] S. Leadley, J. Watts, The use of XPS to examine the interaction of poly (acrylic acid) with oxidised metal substrates, Journal of electron spectroscopy and related phenomena, 85 (1997) 107-121.

[84] M. Ni, B.D. Ratner, Differentiating calcium carbonate polymorphs by surface analysis techniquesan XPS and TOF-SIMS study, Surface and Interface Analysis, 40 (2008) 1356-1361.

[85] H. Petitjean, K. Tarasov, F. Delbecq, P. Sautet, J.M. Krafft, P. Bazin, M.C. Paganini, E. Giamello, M. Che, H. Lauron-Pernot, G. Costentin, Quantitative Investigation of MgO Brønsted Basicity: DFT, IR, and Calorimetry Study of Methanol Adsorption, The Journal of Physical Chemistry C, 114 (2010) 30083016. 
[86] C. Di Valentin, A. Del Vitto, G. Pacchioni, S. Abbet, A.S. Wörz, K. Judai, U. Heiz, Chemisorption and Reactivity of Methanol on MgO Thin Films, The Journal of Physical Chemistry B, 106 (2002) 1196111969.

[87] K. Tanaka, S. Matsuzaki, I. Toyoshima, Photodecomposition of adsorbed methoxy species by UV light and formaldehyde adsorption on silicon (111) studied by XPS and UPS, The Journal of Physical Chemistry, 97 (1993) 5673-5677.

[88] D. Cornu, H. Guesmi, G. Laugel, J.-M. Krafft, H. Lauron-Pernot, On the relationship between the basicity of a surface and its ability to catalyze transesterification in liquid and gas phases: the case of $\mathrm{MgO}$, Physical Chemistry Chemical Physics, (2015).

[89] Y.O.a.T. Baba, Catalysis. Volume 15. Strong Solid Bases for Organic Reactions, The Royal Society of Chemistry, Cambridge, UK,, 2000.

[90] S. Yashonath, P. Basu, A. Srinivasan, M. Hedge, C. Rao, Photoelectron spectroscopic studies of the adsorption of organic molecules with lone pair orbitals on transition metal surfaces, in: Proceedings of the Indian Academy of Sciences-Chemical Sciences, Indian Academy of Sciences, 1982, pp. 101128.

[91] W. Que, Y. Zhou, Y. Lam, Y. Chan, C. Kam, Preparation and characterizations of SiO2/TiO2/Yglycidoxypropyltrimethoxysilane composite materials for optical waveguides, Applied Physics A, 73 (2001) 171-176. 